\title{
EDUCAÇÃO: ARTE COMO ARTE DO ROMPIMENTO OU DA DESCONSTRUÇÃO
}

\author{
EDUCACIÓN: EL ARTE COMO ARTE DE ROMPIMIENTO O DESCONSTRUCCIÓN
}

EDUCATION: ART AS ART OF BREAKING OR DECONSTRUCTION

\author{
Pedro DEMO ${ }^{1}$ \\ Maria Cecília de Souza MINAYO ${ }^{2}$ \\ Renan Antônio da SILVA ${ }^{3}$
}

RESUMO: Educação formal é, mormente, a escolar, feita numa instituição ad hoc, em parte compulsória (constitucional), com legislação própria, em geral rígida, com tonalidades domesticadoras flagrantes e oferecida por profissionais exclusivos. Esta visão analítica pode pender para uma crítica ácida, mas, antes de mais nada, faz uma constatação natural no mundo da vida: as instituições são ambíguas por natureza, tal qual a própria vida e suas espécies. Família, uma das instituições biológicas mais fundamentais e fundantes da sociedade também é ambígua: muitas são o lugar ideal para alguém se criar; nem todas, porém, e sem culpa quiçá, por conta de condições insuficientes de sobrevivência. Algumas famílias degringolam, se desfazem, tornando-se sua destituição preferível a manter um inferno de convivência impossível. Assim parece ser: a "normalidade" da vida é ambígua, seja porque a politicidade sempre ressurge como componente crucial, mesmo no pano de fundo, ou porque as validades sociais e históricas são relativas, ainda que não relativistas, ou porque humanos são criaturas maleáveis o suficiente para mudar de posição, de condição, de crença etc. Daí segue que educar rigidamente é contraproducente, porque a rigidez da vida é inventada. A vida biológica é plástica.

PALAVRAS-CHAVE: Educação. Arte na educação. Escola. Sociedade.

RESUMEN: La educación formal es principalmente educación escolar, realizada en una institución ad hoc, en parte obligatoria (constitucional), con una legislación propia, generalmente rígida, con tonos flagrantes domesticadores y ofrecida por profesionales exclusivos. Esta mirada analítica puede inclinarse hacia una crítica ácida, pero, ante todo, hace una observación natural en el mundo de la vida: las instituciones son de naturaleza ambigua, como la vida misma y sus especies. La familia, una de las instituciones biológicas más fundamentales y fundamentales de la sociedad, también es ambigua: muchas son el lugar ideal para que alguien se cree a sí mismo; no todos, sin embargo, y quizás sin culpa, debido a las insuficientes condiciones de supervivencia. Algunas familias se desmoronan, se

${ }^{1}$ Universidade de Brasília (UnB), Brasília - DF - Brasil. Professor Emérito. Doutorado em Sociologia pela Universidade do Sarre (Universität des Saarlandes) - Alemanha. Bolsista Produtividade 1B CNPq. ORCID: https://orcid.org/0000-0002-5514-2781.E-mail: lepp@rc.unesp.br

${ }^{2}$ Fundação Oswaldo Cruz (FIOCRUZ), Rio de Janeiro - RJ - Brasil. Professora Emérita. Doutorado em Saúde (FIOCRUZ). Bolsista Produtividade 1A CNPq. ORCID: https://orcid.org/0000-0001-6187-9301. E-mail: lepp@rc.unesp.br

3 Centro Universitário do Sul de Minas (UNIS), Varginha - MG - Brasil. ORCID: Pesquisador Titular no Departamento de Pesquisa. Doutorado em Educação Escolar (UNESP). ORCID: https://orcid.org/0000-00031171-217X. E-mail: r.silva@unesp.br 
desmoronan, por lo que es preferible el despido a mantener un infierno viviente imposible. Así parece ser: la "normalidad" de la vida es ambigua, ya sea porque la politicidad siempre reaparece como un componente crucial, incluso en un segundo plano, o porque las validez sociales e históricas son relativas, aunque no relativistas, o porque los humanos somos criaturas maleables lo suficiente para cambiar de posición, condición, creencia, etc. De ahí se sigue que educar estrictamente es contraproducente, porque la rigidez de la vida está inventada. La vida biológica es plástica.

PALABRAS CLAVE: Educación. El arte en la educación. La escuela. La sociedad.

ABSTRACT: Formal education is mainly school education, carried out in an ad hoc institution, partly compulsory (constitutional), with its own legislation, generally rigid, with blatant domesticating tones and offered by exclusive professionals. This analytical view may lean towards an acid criticism, but, first of all, it makes a natural observation in the world of life: institutions are ambiguous in nature, just like life itself and its species. Family, one of the most fundamental and foundational biological institutions in society, is also ambiguous: many are the ideal place for someone to create themselves; not all, however, and perhaps without guilt, due to insufficient conditions for survival. Some families fall apart, crumble, making preferable its dismissal to maintaining an impossible living hell. So it seems to be: the "normality" of life is ambiguous, either because politicity always reappears as a crucial component, even in the background, or because social and historical validities are relative, even if not relativistic, or because humans are malleable enough creatures to change position, condition, belief etc. Hence it follows that educating strictly is counterproductive, because the rigidity of life is invented. Biological life is plastic.

KEYWORDS: Education. Art in education. School. Society.

\section{Introdução}

O tema da educação como arte, não só como ciência ou tecnologia, tem grande interesse porque arte é a porta mais comum de entrada da rebeldia inovadora, crítica, desconstrutiva. A proposta de Steiner da "educação como arte" (STEINER et al., 1988) é um testemunho eloquente, também porque Steiner foi um enorme artista da educação (1995; 1996). A posição de Zimmermann (2001) sobre a pedagogia Waldorf, como arte da educação, também ressalta esta dimensão, que contém, ademais, o sentido superlativo do cuidado com a criança, tomada como protagonista de sua história e sujeito pleno de direitos. Lembremos que Huxley (1882), na segunda metade do século XIX falava de educação como ciência e arte; no começo da segunda metade do século XX, Ziegfield, no âmbito da UNESCO, fazia a conexão íntima entre educação e arte (1954). Black, no fim da primeira parte do século XX (1944), trabalhou a concepção de educação como arte e disciplina. O interesse pela temática se mantém. 
Lembremos que no texto afamado e alarmista A Nation at Risk $k^{4}$ (1983), do governo americano, citado em texto anterior, extremamente atrelado à supremacia americana econômica, a arte constava como referência importante formativa. "Arte não pode ser ensinada; pode ser aprendida; é descoberta" (RACHELLE, 2014). Aí temos uma percepção clarividente: educação como resultado do ensino é treinamento; arte não combina com treinamento, porque vem de dentro; não pode ser depositada lá por outrem de fora. Mas pode ser aprendida, porque aprender é autoria (DAVIS, 2005; GUNVE, 2017; KISIDA; BOWEN, 2019; KRISTIANSEN et al., 2017; BICKEL; CARTER, 2020). Rovelli (2014), sem meias palavras, afirma que "ciência é rebelião", já que "conhecimento depende de jogar fora o que pensamos". Natale (2012) posiciona-se frontalmente: "educação é arte - não ciência". Esta asserção é taxativa demais, porque educação pode ser ambas, arte e ciência, mesmo que muitos vejam o lado da arte como mais condizente. Grande parte dos professores que gosta de cuidar da aprendizagem das crianças percebe nitidamente que sua profissão, tendo necessariamente base científica, tem como fundamento maior a dimensão da arte, assim como as mães tenderiam a ver seu métier materno também como competência técnica, prática, mas erigir um filho útil para a sociedade e bem realizado é arte finória. Assim percebem também orientadores acadêmicos, em especial de mestrado e doutorado: sua função é vista como técnica profissional, mas sua realização mais profunda é gerar um novo mestre que voa sozinho, e isto é principalmente obra de arte (MINAYO, 2019).

\section{Arte como arte do rompimento ou da desconstrução}

Talvez não seja frutífero contrapor arte e ciência, pura e simplesmente, mas com um tipo (positivista, determinista) de ciência. Lembremos que Dyson (2006) propôs "o cientista como rebelde", não por ideologia política sempre possível, mas pela própria posição desconstrutiva da ciência: esta interpela a realidade e o discurso vigente sobre a realidade, pleiteando que é viável observar de outro modo não canônico, para poder desvelar uma realidade que nunca é o que parece. Galilei mostrou perante o Papa essa rebeldia, não porque quisesse "fazer política", mas para descontruir a visão canônica da realidade, sem base lógicoexperimental. Rasmussen (2018), comparando Smith e Hume, via o primeiro como "o professor" e o segundo como "o infiel” (assim foram rotulados à época pelo status quo); os dois foram amigos superlativos, mesmo com diferenças notáveis de ponto de vista, o que só dignifica

${ }^{4}$ Disponível em: https://www2.ed.gov/pubs/NatAtRisk/intro.html. Acesso em: 5 jul. 2020. 
ainda mais a amizade; enquanto Smith tornou-se logo professor e foi aclamado pelo establishment, Hume nunca chegou à cátedra, porque seria iconoclasta demais. Na prática, a obra de Smith hoje é vista como conservadora ou superconservadora, alimentando discursos da extrema direita também, enquanto Hume persiste como rebelde epistemológico, mesmo no contexto liberal, porque negou à ciência o estatuto de verdade final (a empiria não permite asserções inquestionáveis e nenhum discurso é conclusivo, por mais lógico que possa ser) (HUME, 2007). O que leva a ciência a se autorrenovar sem fim são seus filhos infiéis, aqueles que se negam a dizer amém. Amém cabe na igreja, não na ciência. Neste sentido, há um tipo de ciência que não é o oposto de arte, mas uma de suas versões mais poderosas. É o que aparece na posição tão ostensiva de Rovelli (2014): "ciência é rebelião - conhecimento depende de jogar fora o que pensamos". É o que Harari frisa no Sapiens (2015): conhecimento científico é um engenho de autorrenovação porque se mede contra o que ainda não fez; o que fez, é passado. É como o jogo de futebol passado: se foi vencido ou perdido, já foi; o que importa agora é o próximo jogo, porquanto é tolo querer viver de vitória ou de derrota. O Homo deus, porém (HARARI, 2017), bravateia seus louros, em especial sua empáfia científica, tropeçando nas próprias pernas. Ciência rompedora é a que sabe se descartar, ou se autoquestionar. Teorias, por mais que possam ser obras primas, são reconstruções que implicam desconstruções (estas são fundantes; as outras são decorrentes), num moinho inesgotável de renovações provisórias ou num vaivém infinito de passagens retomadas. O que há de melhor nas teorizações, ao lado do rigor metódico ou da formulação perspicaz, é a leveza de sua insignificância quando pretende dar conta da realidade, por serem apenas expressões reducionistas, aproximativas, de algo muito maior que não abarcamos. O que fica fora é o que move a ciência; o que já entrou, é lugar comum.

Epistemologicamente falando, ciência nasce na desconstrução: i) primeiro, desconstrói a realidade, porque a realidade nunca é o que parece; se fosse, não haveria nada a explicar; ii) segundo, desconstrói os discursos vigentes sobre a realidade, porque estão defasados, são olhos do passado, e a vida continua, em especial a aprendizagem. A escola é impérvia a esta dinâmica epistemológica, porque, apegada a um currículo sacralizado como amuleto tolo, não é capaz de assumir que, perante o currículo, o que importa é desconstruir, para logo reconstruir, não repassar o que já é defunto. Por isso, a imagem mais certeira do currículo é a do cemitério: cadáveres do passado. Para voltarem ao presente e terem significação futura, cumpre desconstruir e reconstruir. A reconstrução é crucial, igualmente, mas é decorrente; fundante é a desconstrução. Daí que "saber pensar é questionar" (DEMO, 2010). Aí está a proximidade com arte: nenhum conhecimento é mais rompedor que arte, porque arte, primeiro, nega a 
realidade (é muito pequena para ser tomada a sério, encobre mais do que revela, é só repetição cada vez menos aproveitável); segundo, nega-se a si mesma como algo definitivo: uma vez feita, já se foi, já é passado; precisamos de nova arte; pode até continuar valendo milhões de dólares (um quadro de Picasso, digamos), mas é obra do passado. O que mais importa é um novo Picasso, contra Picasso, além de Picasso.

Arte é difícil de definir, talvez nem se possa definir, porque depende da experiência subjetiva de cada qual, assim como ela mesma é um misto de emoção e racionalidade, onde prevalece, de longe, a emoção no seu autor. Mas podemos divisar alguns traços mais ou menos comuns, em especial a função de rebeldia perante a realidade e o discurso sobre a realidade. Nas epistemologias da vida, a mais radical é a arte, porque toma a realidade como objeto de desconstrução inclemente. Embora "natureza morta" sobretudo na fotografia (porque usa retratos de paisagens inanimadas ou seres vivos, animais, humanos para revitalizar questionamentos, sobretudo chocar [desconstruir] o espectador), a arte mais dinâmica e rompedora é a que "deforma" a realidade (quadro ao lado da Guernica de Picasso), deixando a mensagem frontal de que, para entender a realidade, há que desconstruíla, até mesmo violentamente. Realidade é camuflagem, superfície mentirosa, aparência tergiversadora, como é a maquiagem: serve para encobrir a realidade, enfeitando o que não se gostaria de revelar e ver por baixo. É também modo de chamar a atenção, pelo insólito, chocante, avesso, já que o lado direito da realidade é maquiagem; ela é, no fundo, torta, convulsionada, caótica, feiosa, irreconhecível. O artista não interpreta sua arte, deixa, quando é uma pintura, um título, só. Faz isso porque, sendo expressão subjetiva, ele mesmo não tem uma interpretação final. Se fosse fazer outro quadro com o mesmo título agora, não faria este de novo, porque este quadro é passado. Mesmo na pintura plagiada, adrede plagiada, temos outro quadro com outro "autor" (mesmo contraventor). Segundo Minayo, Demo e Silva (2020), entende-se que a educação pode contribuir para uma mudança de qualquer cenário; de modo especial, educação de qualidade.

Arte abrange espectro infinito de manifestações, além da pintura (quadro acima), incluindo artes cênicas, música, arquitetura, escultura, interiores/exteriores, etc. Em todas o traço mais brilhante é a divergência com a realidade e o discurso sobre a realidade. Os gregos antigos, no teatro, buscavam interpelar a vida, o sentido da vida, a sociedade, as hipocrisias, as fake news... O público era convidado a se chocar, sensibilizar, para mudar o entendimento das coisas e de si mesmos. Algumas artes são mais acomodatícias, caprichando na emoção, como

${ }^{5}$ Disponível em: https://en.wikipedia.org/wiki/Still_life. Acesso em: 5 jul. 2020. 
a música clássica e gregoriana, mas, a seu modo, também saem da rotina, trazem dimensões do belo em circunstâncias surpreendentes. Preferindo a sonoridade, o acorde perfeito, a música se repete apenas, e por isso música moderna ou popular, ou divergente (rock pesado, por exemplo), recorre a outros expedientes (desafinações, gritos, tambores ruidosos, danças frenéticas, alucinações) para tirar a plateia do sério. Nada é mais tolo do que ser sério: não muda o semblante, o comportamento, é previsível, manipulado por dentro e por fora. Talvez o oposto mais oposto da arte seja rotina, a vida como mentira. A poesia, por sua vez, implica a rebeldia frente à gramática, aos sentidos estabelecidos, embora não dispense a gramática (esta não é o oposto da poesia, é o pano de fundo ordenado que ressalta a divergência de sentido), assim como a vida não dispensa o DNA - este parece fixo, repetitivo, mas a vida em si nunca se repete. Quando Vinicius diz "o amor é eterno enquanto dura”, fere o senso comum, a lógica, a expectativa rotineira dos significados; em si, seria afirmação contraditória, indigna de ser tomada a sério. Na prática, é coisa séria, porque formula algo fundamental no amor: a dinâmica rebelde de algo que se quer duradouro, mas é naturalmente fugaz. Nada é mais mentiroso do que juras de amor eterno - metade dos casamentos se separam, muitos casais convivem por teimosia... - porque paixão não é amor; enquanto a primeira é tipicamente impulsiva e passageira, amor pode deixar traços mais longos, mas se dilui também, porque tudo se dilui, a vida também (DEMO, 2020a).

A arte recorda, insistentemente, que a vida, para ter algum interesse mais autêntico, precisa mudar todo dia - não é um modo de ser, é de vir-a-ser, de se contrapor, contestar, como é a vida em si: uma dinâmica que, sendo física, não aceita ser só isso (KAUFMAN, 2019; DAVIES, 2019; LASZLO et al., 2016; GOBER, 2018), é material e imaterial, é natural e transcendente, é e não é! A arte não se refere apenas ao "belo", porque o belo, em geral, é fútil, como é um rosto belo; logo vêm as rugas!... O "belo" fundamental e fundante é aquele que bagunça o correto, confunde tudo, vira pelo avesso, prefere a desordem: enquanto a ciência busca na desordem padrões de ordem, a arte busca na ordem a desordem, porque esta é generativa; a ordem é morta. Para a arte, morremos, não porque a vida termina, mas porque já não nos suportamos, nem outros nos suportam, porque o mofo domina o alongamento. O que mata a vida é o mofo. Quando nos deixamos enlevar por uma obra de arte, valorizamos a divergência, o que transparece, como raio de luz, na escuridão da mesmice. A arte tem pavor da reprodução, da aula.

Hoje, a direita extremista pede o retorno aos "valores sagrados" de uma identidade reprodutiva retrógrada, porque postula estruturas imutáveis, crenças inquestionáveis, posicionamentos divinos (cita-se a verdade evangélica que liberta, João 8:32, para engambelar 
os devotos que, manipulados pela hierarquia perversa, confundem a graça com o dízimo), tendo ao fundo apenas a pretensão de chegar ao poder e daí não sair mais. Todas as religiões cristãs têm este vício intestino (BELLAH, 2011), porque forjaram um deus mais humano que os humanos, sobretudo o do Antigo Testamento, que aceita todas as malandragens politiqueiras (reinos, prosperidade, enriquecimento, supremacias, eliminação de rivais, golpes etc.). Cristo nunca foi "próspero": o capital dele sempre foi R\$Nada, ou R $\$ 0$ ! Absolutamente nada. Disse que seu reino não era deste mundo, mas aquele do Papa, do Edir Macedo, do Malafaia é só deste mundo - eles não creem em Deus, porque não são representantes de Deus; Deus é seu representante, fala o que eles querem, como quando se cita João 8:32: Deus é marionete do Edir Macedo, como é de governantes fundamentalistas da extrema direita (DEMO, 2017). Mas há santos, de verdade, não tão santos quanto a Igreja Católica presume, gente que diverge totalmente do materialismo mercantilista e busca outros valores transcendentais, e, possivelmente, o Papa Francisco possa ser incluído aí, ou São Francisco (BOFF, 2006; 2007; HARRIS, 2014). Religião pode ser arte, quando incide sobre mudanças inacreditavelmente radicais de vida, em nome de alternativas sublimes. Não pode ser arte a religião que gira em torno do dízimo ou de contas bancárias.

Embora seja um tipo de interpretação esta que faço aqui da arte - como rebelião essencialmente (KIPLING, 1901; RADCLIFFE, 2009; PARKER; WELCH, 2017) - estou apostando que é a mais interessante e pertinente, porque rima com a vida: irrequieta, exuberante, alternativa, jeitosa, provocativa... A tudo desconstrói, porque nada que é real vale a pena - só o irreal vale a pena, a utopia (CLARK et al., 2009; MERZ; KNORR CETINA, 1997; KAU, 2001) - pois o parâmetro da realidade não é o que existe, mas o que ainda não existe, a potencialidade, o que pode vir-a-ser, como propunha Bloch em seu princípio "esperança" e em sua ontologia do "ainda-não-ser" (1959; 1961). Quem se contenta com a realidade que tem, já faleceu. A ciência pode ser uma rotina positivista enfadonha, reprodutiva, até mesmo imbecilizante, mas pode ser também a rebelião (CONSTANTIN, 2020; BHASKAR, 2003), a divergência criativa, a busca de outras dimensões de uma realidade que não pode ser parâmetro para a vida; a vida deve ser parâmetro da realidade (DAVIES, 2019).

\section{Escola e arte}

Primeiro, vamos reconhecer que a escola ainda mantém arte no currículo (BNCC, 2018, p. 193), embora com tratamento variado, pouco coerente. No EF, aparece nas linguagens e é tomada como referência curricular específica (conteúdos específicos: artes visuais, dança, 
música, teatro). No EM, arte é um princípio geral de abordagem da realidade, talvez mais coerente com a importância da arte como componente formativo, mas está "perdido" na multidão curricular. O tom é saber apreciar o fenômeno da arte, não aparecendo devidamente sua relevância formativa, como capacidade de autorias alternativas, embora se acentuem sua multiplicidade, multiculturalidade, complexidade (2018, p. 193). A indicação de que os alunos são desafiados a serem protagonistas e criadores é muito pertinente, compartilhando saberes e produções, também performances e exibições. "A prática investigativa constitui o modo de produção e organização dos conhecimentos em Arte", sugerindo atividades de aprendizagem voltadas para o estudante, não apenas ensino (Ib.). Definem-se, então, seis dimensões do conhecimento que marcam a singularidade da experiência artística: i) criação: referência à autoria imprescindível; ii) crítica: inclui novas compreensões das relações com a realidade; iii) estesia: referência a experiência sensível com percepções alternativas; iv) expressão: capacidade de exteriorizar e manifestar as criações subjetivas; v) fruição: deleite da arte; vi) reflexão: construir argumentos e ponderações sobre as fruições, experiências e processos criativos, artísticos e culturais (Idem, p. 195).

A proposta é pertinente, tem noção da condição alternativa da formação artística; atrapalha esta visão o contexto geral da BNCC, por ser uma proposta que camufla sob “aprendizagens essenciais" vezos antiquados de "ensinagem" (DEMO, 2019; 2019a), codificadas rigidamente pedaço a pedaço, disciplinarmente. Reconhece que é imprescindível "a recriação da escola" (BNCC, 2018, p. 462), mas o ambiente continua instrucionista como sempre, também porque depende totalmente da atuação docente, que persiste a mesma. Os arteeducadores que participaram da formulação da BNCC incluíram "competências específicas" para o EF em geral pertinentes:

Quadro 01 - Competências e observações

\begin{tabular}{|c|c|}
\hline & \\
\hline $\begin{array}{l}\text { 1. Explorar, conhecer, fruir e analisar criticamente } \\
\text { práticas e produções artísticas e culturais do seu } \\
\text { entorno social, dos povos indígenas, das } \\
\text { comunidades tradicionais brasileiras e de diversas } \\
\text { sociedades, em distintos tempos e espaço, para }\end{array}$ & $\begin{array}{l}\text { Formulação pertinente em muitos } \\
\text { sentidos, sobretudo da diversidade } \\
\text { cultural e artística; está menos } \\
\text { explícito o desafio de participar dessa } \\
\text { produção, como projeto formativo; a } \\
\text { relação pedagógica (formativa) }\end{array}$ \\
\hline
\end{tabular}




\begin{tabular}{|c|c|}
\hline ogar com as diversidades. & $\begin{array}{l}\text { precisaria estar mais desenvolvida } \\
\text { porque é o que interessa afinal. }\end{array}$ \\
\hline $\begin{array}{l}\text { 2. Compreender as relações entre as linguagens da } \\
\text { Arte e suas práticas integradas, inclusive aquelas } \\
\text { possibilitadas pelo uso das novas tecnologias de } \\
\text { informação e comunicação, pelo cinema e pelo } \\
\text { audiovisual, nas condições particulares de } \\
\text { produção, na prática de cada linguagem e nas suas } \\
\text { articulações. }\end{array}$ & $\begin{array}{l}\text { Formulação pertinente, em particular } \\
\text { por incluir novas tecnologias, } \\
\text { sobretudo digitais; é pouco, porém, } \\
\text { "compreender”, porque a postura } \\
\text { analítica é instrumental ao processo } \\
\text { formativo esperado, que fica } \\
\text { obnubilado num pano de fundo } \\
\text { obscuro. }\end{array}$ \\
\hline $\begin{array}{l}\text { 3. Pesquisar e conhecer distintas matrizes estéticas } \\
\text { e culturais - especialmente aquelas manifestas na } \\
\text { arte e nas culturas que constituem a identidade } \\
\text { brasileira -, sua tradição e manifestações } \\
\text { contemporâneas, reelaborando- -as nas criações em } \\
\text { Arte. }\end{array}$ & $\begin{array}{l}\text { Pertinente como conteúdo, mas pálida } \\
\text { por requerer apenas "pesquisar e } \\
\text { conhecer", quando é fundamental } \\
\text { desconstruir e reconstruir como } \\
\text { processo autoral formativo. }\end{array}$ \\
\hline $\begin{array}{l}\text { 4. Experienciar a ludicidade, a percepção, a } \\
\text { expressividade e a imaginação, ressignificando } \\
\text { espaços da escola e de fora dela no âmbito da Arte. }\end{array}$ & $\begin{array}{l}\text { O usufruto é parte importante, mas o } \\
\text { mais relevante é "ressignificar" } \\
\text { espaços escolares e não escolares, } \\
\text { objetivo apenas esboçado. }\end{array}$ \\
\hline stica. & $\begin{array}{l}\text { Texto lacônico, para constar. Seria } \\
\text { muito relevante saber recriar o mundo } \\
\text { digital como espaço da arte. }\end{array}$ \\
\hline $\begin{array}{l}\text { 6. Estabelecer relações entre arte, mídia, mercado e } \\
\text { consumo, compreendendo, de forma crítica e } \\
\text { problematizadora, modos de produção e de } \\
\text { circulação da arte na sociedade. }\end{array}$ & $\begin{array}{l}\text { Formulação muito pertinente, mas } \\
\text { perde a chance de realçar sobretudo a } \\
\text { inserção do estudante em tais espaços } \\
\text { de arte. }\end{array}$ \\
\hline $\begin{array}{l}\text { 7. Problematizar questões políticas, sociais, } \\
\text { econômicas, científicas, tecnológicas e culturais, } \\
\text { por meio de exercícios, produções, intervenções e } \\
\text { apresentações artísticas. }\end{array}$ & $\begin{array}{l}\text { Proposição muito apropriada, que } \\
\text { dignifica a inserção da arte na } \\
\text { formação dos estudantes. }\end{array}$ \\
\hline
\end{tabular}




\begin{tabular}{|l|l|}
\hline $\begin{array}{l}\text { 8. Desenvolver a autonomia, a crítica, a autoria e o } \\
\text { trabalho coletivo e colaborativo nas artes. }\end{array}$ & $\begin{array}{l}\text { Muito boa formulação, podendo-se } \\
\text { acrescentar à atividade crítica, a } \\
\text { autocrítica. }\end{array}$ \\
\hline $\begin{array}{l}\text { 9. Analisar e valorizar o patrimônio artístico } \\
\text { nacional e internacional, material e imaterial, com } \\
\text { suas histórias e diferentes visões de mundo. }\end{array}$ & $\begin{array}{l}\text { conter o cuidado com colonialismos a } \\
\text { título de permutas artísticas. }\end{array}$ \\
\hline
\end{tabular}

Fonte: elaborado pelos autores

Em termos de formulação teórica, o texto é pertinente, também interessante, por vezes inovador e afinado com expectativas formativas críticas e autocríticas, ou alternativas. Estando Arte no capítulo da Linguagem, não parece ter havido prejuízo mais visível, a não ser o contexto instrucionista da BNCC como um todo. Lembre-se que a BNCC ainda conserva o termo "reproduzir" (aparece ao todo 15 vezes nas habilidades dos anos iniciais: 3 vezes, à p. 105; 2 vezes à $\mathrm{p} .107 ; 2$ vezes à $\mathrm{p} .111 ; 4$ vezes à $\mathrm{p} .123 ; 1$ vez à $\mathrm{p} .127 ; 3$ vezes à $\mathrm{p} .131)$, como se reproduzir pudesse ser habilidade. É precisamente o avesso. Este resquício de instrucionismo cru apenas confirma que "aprendizagens essenciais" são "ensinagens" instrucionistas. Habilidades, naturalmente, são formuladas como "verbos", o que indicaria alguma "metodologia ativa"; mas esta tática oculta o repasse de conteúdo, camuflado sob verbos aparentemente sugestivos (DEMO, 2019, p. 38).

No âmbito do EM, a estruturação muda de figura, optando-se por manejo interdisciplinar: arte está espraiada nos conteúdos variados, como princípio formativo. "A Arte, enquanto área do conhecimento humano, contribui para o desenvolvimento da autonomia reflexiva, criativa e expressiva dos estudantes, por meio da conexão entre o pensamento, a sensibilidade, a intuição e a ludicidade. Ela é, também, propulsora da ampliação do conhecimento do sujeito sobre si, o outro e o mundo compartilhado. É na aprendizagem, na pesquisa e no fazer artístico que as percepções e compreensões do mundo se ampliam e se interconectam, em uma perspectiva crítica, sensível e poética em relação à vida, que permite aos sujeitos estarem abertos às percepções e experiências, mediante a capacidade de imaginar e ressignificar os cotidianos e rotinas" (BNCC, 2018, p. 482). A formulação chega a ser charmosa, mas o contexto escolar está em outra direção, completamente oposta, logo no EM, onde a aprendizagem é totalmente peregrina (DEMO, 2020). Uma coisa é a teorização, relativamente avançada, outra é a prática, perdida no instrucionismo mais aviltado. Chega a ser cínico postular que o EM se inspire na rebelião da arte, que penetre a matemática (o maior desastre pedagógico escolar), a língua portuguesa (caindo aos pedaços, regredindo em 
desempenho), que se ancore em aprendizagem, pesquisa e fazer artístico: a árvore se conhece por seus frutos! O texto corresponde, teoricamente, à expectativa da "recriação da escola" (BNCC, 2018, p. 462), exemplificada no itinerário formativo, projeto de vida, protagonismo estudantil, expressões muito importantes, mas retiradas de ambientes neoliberais motivacionalistas, que praticam despudoradamente o instrucionismo que é via única de “aprendizagem”. Elas não introduziram nenhuma inovação relevante na escola privada, que continua estagnada clamorosamente, porque as pretensões de mudança em favor da aprendizagem autoral do aluno esbarram - e aí sucumbem - em práticas reprodutivas do arco da velha, cujo resultado é fácil de observar no Enem: quase ninguém sabe redigir, apenas catar resposta certa para questões que, como regra, não mobilizam autorias - de 4 milhões de candidatos, uns 50 ("cinquentinha") redigem bem, porque autoria estudantil não tem importância nenhuma na escola.

De si, a formulação é melhor que a do EF, porque se toma Arte como princípio formativo comum a todos os conteúdos, mas não é crível, porque a BNCC persiste conteudista ao final, em especial porque o ambiente escolar não muda por lei, de cima: sendo o professor o mesmo, a aula a mesma, a prova a mesma, a organização escolar a mesma, tudo deverá ficar na mesma. Por exemplo, para a recriação da escola é imprescindível mudar o professor. É certo que a universidade não vai acolher qualquer mudança neste sentido, porque não tem autocrítica nenhuma. Itinerário formativo pede outra organização escolar, principalmente a superação dos 45 minutos de aula, que não servem a qualquer atividade de aprendizagem minimamente decente. Não temos dados mais concretos sobre os resultados da Arte na escola, mas podemos usar um artifício indireto de avaliação (apenas aproximativo e sugestivo), observando o desempenho em língua portuguesa, tendo em vista que Arte está no espaço da Linguagem. Na Tabela 1, podemos observar o aprendizado adequado no EM, na média nacional (Brasil) e nos estados. Na média (Brasil), o aprendizado adequado começou com 45.4\% em 1995, chegou a cambalear para $22.6 \%$ em 2005 e ficou em $29.1 \%$ em 2017, marcando um recuo de $16.3 \%$ em 22 anos, um resultado muito catastrófico, que justifica plenamente a solicitação da BNCC de "recriação da escola": de fato, a escola que temos não só não produz aprendizagem, está andando para trás. 
Tabela 1 - Aprendizado adequado em LÍNGUA PORTUGUESA no EM - IDEB - BRASIL e Estados (1995-2017) (\%)

\begin{tabular}{|c|c|c|c|c|c|c|c|c|c|c|c|c|}
\hline Anos & 1995 & 1997 & 1999 & 2001 & 2003 & 2005 & 2007 & 2009 & 2011 & 2013 & 2015 & 2017 \\
\hline Brasil & 40 & 39.7 & 27.6 & 25.8 & 26.9 & 22.6 & 24.5 & 28.9 & 29.2 & 27.2 & 27.5 & 29.1 \\
\hline Pará & 32.4 & 37.9 & 12.9 & 19.3 & 16.0 & 14.2 & 13.3 & - & 26.1 & 14.8 & 19.0 & 15.6 \\
\hline Maranhão & 19.2 & 24.9 & 14.7 & 15.4 & 26.3 & 09.6 & 13.3 & 16.1 & 15.3 & 12.2 & 15.1 & 16.4 \\
\hline Amazonas & 36.6 & 23.8 & 12.5 & 13.0 & 14.8 & 06.4 & 09.9 & - & 20.3 & 14.6 & 23.7 & 16.6 \\
\hline Amapá & 37.5 & 14.2 & 15.1 & 18.5 & 21.2 & 19.8 & 15.1 & - & 20.0 & 17.4 & 18.2 & 17.0 \\
\hline Roraima & 27.9 & 19.8 & 6.8 & 12.1 & 14.4 & 19.1 & 15.0 & - & 20.2 & 18.8 & 22.2 & 18.2 \\
\hline Bahia & 30.4 & 48.5 & 18.9 & 17.9 & 21.5 & 14.8 & 17.2 & 26.1 & 21.6 & 16.2 & 17.5 & 18.4 \\
\hline Alagoas & 35.6 & 25.9 & 15.9 & 17.7 & 21.8 & 15.5 & 13.5 & 16.8 & 15.4 & 12.6 & 15.9 & 19.1 \\
\hline Rio Gr. Norte & 27.5 & 35.6 & 14.7 & 17.8 & 18.8 & 15.2 & 17.0 & 19.6 & 18.2 & 15.6 & 18.5 & 20.6 \\
\hline Piauí & 21.7 & 41.0 & 20.3 & 23.9 & 24.3 & 16.7 & 15.1 & 16.2 & 18.8 & 18.9 & 20.7 & 21.3 \\
\hline Tocantins & 26.0 & 29.4 & 06.3 & 13.7 & 13.1 & 13.3 & 13.0 & - & 20.2 & 16.9 & 17.5 & 22.1 \\
\hline Acre & 23.9 & 18.5 & 11.4 & 17.1 & 23.6 & 17.5 & 21.4 & - & 19.2 & 21.7 & 21.7 & 22.9 \\
\hline Mato Grosso & 36.4 & 37.8 & 24.0 & 25.8 & 22.5 & 21.4 & 18.3 & 21.0 & 24.4 & 20.3 & 23.7 & 23.7 \\
\hline Paraíba & 28.6 & 28.5 & 22.5 & 16.9 & 18.1 & 12.6 & 18.8 & 23.4 & 21.5 & 22.6 & 22.0 & 23.8 \\
\hline Rondônia & 49.0 & 32.9 & 20.6 & 19.9 & 19.9 & 20.4 & 17.7 & - & 24.2 & 24.2 & 24.2 & 26.3 \\
\hline Sergipe & 44.2 & 45.1 & 20.1 & 18.8 & 21.1 & 21.2 & 14.5 & 25.3 & 20.4 & 19.2 & 23.0 & 27.2 \\
\hline Ceará & 29.0 & 37.5 & 22.1 & 18.8 & 24.9 & 20.1 & 20.4 & 25.2 & 24.0 & 21.2 & 21.5 & 27.4 \\
\hline Pernambuco & 22.3 & 35.0 & 17.5 & 15.6 & 19.0 & 16.6 & 19.1 & 20.7 & 20.1 & 25.0 & 27.7 & 28.6 \\
\hline Mt. Grosso Sul & 42.4 & 42.0 & 26.1 & 31.4 & 30.5 & 29.6 & 28.4 & 42.4 & 37.6 & 32.5 & 34.1 & 30.4 \\
\hline Paraná & 49.1 & 46.9 & 30.8 & 22.4 & 28.6 & 25.6 & 29.9 & 37.4 & 31.9 & 27.3 & 33.2 & 32.8 \\
\hline São Paulo & 57.6 & 33.9 & 29.9 & 29.7 & 26.4 & 25.5 & 28.3 & 33.6 & 35.9 & 35.9 & 32.3 & 33.3 \\
\hline Santa Catarina & 49.2 & 41.9 & 31.4 & 30.9 & 63.6 & 25.7 & 27.1 & 31.8 & 35.5 & 31.5 & 32.8 & 33.9 \\
\hline Goiás & 49.6 & 43.7 & 26.7 & 25.0 & 25.9 & 17.6 & 18.3 & 27.0 & 26.3 & 28.6 & 28.9 & 33.9 \\
\hline Minas Gerais & 48.5 & 65.2 & 32.4 & 25.9 & 29.5 & 28.1 & 31.6 & 32.0 & 35.6 & 30.2 & 30.0 & 34.7 \\
\hline Rio de Janeiro & 38.8 & 31.5 & 38.9 & 31.6 & 37.5 & 23.6 & 26.9 & 30.3 & 38.1 & 36.0 & 34.4 & 35.0 \\
\hline Rio Gr. Sul & 57.5 & 60.2 & 34.9 & 42.8 & 39.5 & 33.6 & 34.8 & 45.1 & 36.3 & 37.9 & 32.4 & 36.5 \\
\hline $\begin{array}{l}\text { Distrito } \\
\text { Federal }\end{array}$ & 65.5 & 55.8 & 42.8 & 40.9 & 39.4 & 40.6 & 43.3 & 38.4 & 40.3 & 40.2 & 41.1 & 39.3 \\
\hline Espírito Santo & 33.0 & 45.9 & 29.4 & 26.4 & 31.2 & 25.7 & 23.7 & 36.0 & 29.4 & 28.6 & 35.9 & 40.7 \\
\hline
\end{tabular}

Fonte: MEC, Inep. Ranking pela última coluna - elaborado pelos autores

O estado mais bem posicionado foi Espírito Santo, com $40.7 \%$ de aprendizado adequado em língua portuguesa em 2017, um raro exemplo de progresso desde 1995, quando teve 33\% (o outro exemplo é Pernambuco: começa com $22.3 \%$ e chega a $28.6 \%$ ). A cifra de $40.7 \%$ (a única que atinge $40 \%$ ) é ainda minúscula, totalmente insatisfatória e excepcional no cômputo geral. Todos os outros estados recuaram no desempenho, alguns de modo impressionante, como São Paulo: começou em 1995 com 57.6\%, mas chega a 2017 com somente 33.3\% (24.3\% perdidos). Distrito Federal começou com $65.5 \%$ e desceu para $39.3 \%$ (perda de $26.2 \%$ ). São sete os estados que tiveram desempenho abaixo dos 20\% em 2017: Pará, o mais mal posicionado, com 15.6\%; Maranhão com 16.4\%; Amazonas, com 16.6\%; Amapá, com 17\%; 
Roraima, com 18.2\%; Bahia, com 18.4\%; Alagoas, com 19.1\%. Todos também recuaram no período. Trata-se de um desempenho absurdamente insuficiente, indicando completa inépcia em dar conta do recado.

Língua Portuguesa está, como regra, em frangalhos e decaindo a olhos vistos, com raríssimas exceções. A julgar por tal desempenho, Arte dificilmente teria outro resultado, o que nos levaria a presumir que Arte é o que em geral é na escola: enfeite eventual, encheção de tempo, fazeção inconsequente. Como princípio fundamental da aprendizagem autoral inexiste, porque o instrucionismo devora tudo. Imaginar que na escola que temos Arte como criação, rebeldia, alternativa, seja referência prática da lide escolar, é um acinte.

\section{A "arte" pelo avesso do instrucionismo}

Aos olhos do PISA o desempenho asiático, chegando aos primeiros lugares, soa como "arte", no sentido imediatista de resultado superior. Como Zhao (2014; 2018; ZHAO et al., 2019) analisa, porém, a proposta instrucionista pode angariar resultados superiores, mas pedagogicamente é infame, porque é opressora, doentia, sufocante (aumentou o suicídio escolar), impingindo aos alunos tirocínios à la trabalhos forçados que não é possível acolher como "pedagógicos" e nisto são o avesso da arte. Como Zhao acentua, daí não saem rebeldes, inovadores, rompedores, mas um exército alinhado para gritar amém. Serve tal sistema de ensino à competitividade e produtividade, atrelado ao sistema produtivo subservientemente, o que é, igualmente, o avesso da arte. Em parte, podemos interpretar, pelo menos tentativamente, que a adoção do liberalismo econômico radical desbragadamente competitivo (MILANOVIC, 2019; PIKETTY, 2020) tem o efeito de “desentupir" os chineses, à medida que podem entregarse freneticamente a atividades econômicas rompedoras, permitidas, incentivadas, quando em outros setores da vida são coibidas. Transparece este "desentumpimento" na obra provocativa de Lee (2018) que aposta na tomada em breve da liderança mundial econômica e tecnológica, junto com a educacional, da China no mundo. Um dos argumentos é o gosto pelo trabalho duro, sobretudo pela competição sem peias, sem tréguas, sem concessão, rompendo tudo a todo momento, para derrubar rivais e postar-se no topo do mercado. Lembra a afamada obra de Schumpeter sobre "destruição criativa" (2009), que ele via como "a arte" do capitalismo, e que acabou se tornando o modus procedendi deste sistema produtivo, em especial na era digital. A capacidade de rompimento se vê, de modo estupendo, em empresas tecnológicas rompedoras como Microsoft, Google, Facebook, Amazon etc. que viraram pelo avesso a economia global, colocando a invenção criativa como alavanca absolutamente fundamental. 
Desta pressão pragmática emergiu a imposição da empregabilidade, a mudança fundamental de preparação para o trabalho com base no potencial criativo do trabalhador, exigindo até mesmo espírito crítico, filosofia, trabalho em equipe, iniciativa, comunicação própria etc., um rol de virtudes que combine com a destruição criativa do sistema produtivo. $\mathrm{O}$ país que hoje mais corresponde a este frenesi é a China, em contexto muito contraditório, porém. Primeiro, a motivação maior da inovação não é formativa, da aprendizagem autoral, mas competição desvairada, agressiva, predatória, que se expressa também na destruição do meio ambiente (cidades pouco habitáveis pela poluição, por exemplo). Não tem a ver com arte como capacidade de romper com a realidade em nome da vida, da libertação, da emancipação, mas em nome do capital. Segundo, os resultados não são pedagógicos, são instrucionistas intestinamente, forçados goela abaixo, em especial na esfera da matemática (ZHAO, 2018). Uma pequena nata de estudantes se liberta do sufoco, porque, com desempenho nas alturas, ganha movimentação própria, sobretudo no campo digital (hackers, engenheiros de software, analíticos digitais etc.). A massa dos estudantes rasteja sufocada pela opressão e se encaixa nos empregos do sistema produtivo subservientemente, destituída por completo de virtudes da Arte como expressão humana, humanizadora, formadora. Na prática, uma proposta da Arte como formação pedagógica pode acarretar a ridicularização, porque retiraria tempo preciso para o que importa: matemática, mormente. Daí a má fama das "humanidades", porque é tolo preencher o espírito, enquanto não se tem o domínio material da economia mundial. Ao final, resta a docilização dos corpos e mentes, não necessariamente produtiva e competitiva - gente dócil é acomodada! - mas ainda muito útil ao sistema porque permite alguma combinação suficiente entre perícia técnica e produtividade.

Para a interpretação de Zhao, a arte que aí aparece é pelo avesso: a arte da imbecilização, da manipulação, da alienação. Não há tempo e espaço para discutir alternativas de vida, novas dimensões da realidade, outros projetos de cooperação coletiva, porque todos, como um exército suicida, se alinham para uma batalha sem sujeitos contra um inimigo sem face, reverberando o mesmo projeto emancipatório eurocêntrico colonizador há 500 anos. Tecnologia, competência industrial, educação de ponta são usadas para colonizar mentes e corpos, porque a sociedade não gira em torno de seus valores cooperativos da qualidade de vida, mas da competitividade ensandecida. Mais que nunca, a análise de Foucault vira profecia: educação é atividade prisional. Crianças fazem trabalhos forçados (RIPLEY, 2013), ralando perto de 20 horas por dia, para poderem engolir matemática, treinar respostas certas, dominar conteúdos a qualquer preço, quantitativamente, com vistas a ocupar o topo. Pedagogicamente é um topo vazio. Em termos de arte, seu avesso. 
No entanto, cabe reconhecer que também entre nós, arte na escola sempre foi farsante, com exceção de professores vocacionados e dedicados que fazem das tripas coração para oferecer aos alunos chances de entender a rebelião formadora possível. Como regra, todos concordamos que arte como rompimento rebelde é uma das expressões humanas mais notáveis, que coloca a espécie numa rota evolucionária extremamente mais complexa e refinada (não "supremacista"). Klein (2002), analisando a aurora da cultura humana, ao invés de qualificar pela produção de instrumentos e armas, prefere frisar como avanço cultural e civilizatório a produção de artesanatos para presentear outras pessoas: fazer um colar de contas, um adereço artístico, um artefato inventado jeitosamente indica a sensibilidade humana mais profunda e promissora, cuja simbologia rompedora está em apontar para dimensões alternativas da vida que a enlevam, edificam, sublimam, não para a competitividade e produtividade. Não por acaso, arte é "inútil" em termos econômicos crus, porque entendemos utilidade como exploração vantajosa, mesmo vil. Um quadro de Picasso vale, hoje, milhões de dólares, mas, como tal, não tem utilidade outra que ficar pendurado na parede para visitação. Para que serve, em termos sociais, o quadro? Não tem serventia material, propriamente, mas sociocultural - Guernica sugere os horrores da guerra civil espanhola, apela para a deformação dos corpos para indicar que a realidade rotineira impede de apreciar/perceber outras realidades, que podemos ver na tela muitas interpretações sob o choque alternativo, que o mundo real em que vivemos é um horror. Podemos sempre alegar que esta mensagem, por mais importante que possa parecer, não produz nada de concreto, não abaixa a inflação, não melhora o salário mínimo... Em termos de utilitarismo imediato, arte é dispensável, já que é comum viver sem arte, uma vida rotineira insípida. O lado forte da arte é interpelar o sentido das coisas, da vida, da humanidade. Para quê? Para nada!

Este nada, contudo, é o que vale tudo, porque dele podemos retirar sentidos alternativos ao que nos parece sem sentido, mundos outros ao que nos emergem como rotina, dimensões chocantes e novas ao que apenas se reproduz para nos envelhecer como peças descartáveis. A escola que temos não tem como apreciar desta forma, porque, embora haja professores safos, muito coerentes, o sistema é uma gargalhada sarcástica contra a rebelião da arte. 


\section{Consideração Finais}

Para que servem as sinfonias de Beethoven? Seria o caso trabalhá-las na escola? Embora exista um mercado para música, música nunca foi propriamente mercadoria, porque é um criação rompedora da mente humana, que não se compra, nem se vende. Levar este tipo de formação para a escola parece veleidade infantilista, porque não enche barriga. A maioria dos pais também pensaria assim: o filho perde tempo com as sinfonias, enquanto precisa é falar inglês, saber matemática, lidar habilmente com computador. No entanto, desde sempre na história humana, o mais importante para o sentido da vida foi também o mais inútil. Religião fala por si: buscar o sentido da vida em outro mundo do qual não temos qualquer noção concreta, parece brincadeira de desocupado. Um monge fechado em seu mosteiro, dedicado à oração e meditação, sustentado pelos outros, é um desocupado flagrante. O normal é o homem comum, assoberbado por preocupações materiais imediatistas, sem tempo para pensar "em outras coisas" que não seja a sobrevivência imediata. Que significa uma sinfonia de Beethoven para quem ganha salário mínimo? A única questão que importaria é em que a sinfonia melhora o salário mínimo?... Não vai! Então, não serve!

A arte serve para desconstruir a inutilidade imediatista que define a vida rotineira, indicando que o retorno mais autêntico, não é material, pecuniário, mas criativo, alternativo. É um vício inaceitável prender as pessoas na sobrevivência imediata, porque esta condição embrutece o espírito, exaspera a agressividade, rebaixa os sentimentos. Na escola, mesmo sendo um mundinho perdido à parte, artificial, as crianças poderiam ter esta experiência de enlevo, sublimação, ao perceberem que a realidade mais importante não é a que temos na mão, mas que nos escapa da mão. O sentido da vida não está nas grosserias imediatistas de uma sociedade afogada em sobrevivência rasa, mas na capacidade de apreciar atividades que não rendem nada, além do deleite de as experimentar e delas sacar indicações alternativas de vida. As crianças chinesas poderiam ter algum senso de felicidade mais autêntica se vissem em educação uma atividade não imediatista, competitiva, produtiva, mas formativa, onde o que mais vale é sempre de graça. 


\section{REFERÊNCIAS}

BASE NACIONAL COMUM CURRICULAR (BNCC). Educação é a Base. Brasília: Ministério da Educação, 2018. Disponível em:

$\mathrm{http} / / /$ basenacionalcomum.mec.gov.br/images/BNCC_EI_EF_110518_versaofinal_site.pdf. Acesso em: 20 set. 2020.

BELLAH, R. N. Religion in Human Evolution: from the Paleolithic to the axial age. The Belknap Press of Harvard University Press, Cambridge. 2011.

BHASKAR, R. From science to emancipation: alienation and the actuality of Enlightenment. Sage. 2003.

BICKEL, B. A.; CARTER, M. (Eds.). Studies in arts-based educational research. Springer, 2020

BLACK, M. Education as art and discipline. Ethics, v. 54, n. 4, p. 290-294, 1944

BLOCH, E. Das prinzip hoffnung. Frankfurt: Suhrkamp, 1959. v. 2

BLOCH, E. Zur ontologie des noch-nicht-seins. Frankfurt: Suhrkamp, 1961.

BOFF, L. Espiritualidade: um caminho de transformação. São Paulo: GMT, 2006.

BOFF, L. São Francisco de Assis. Petrópolis: Vozes, 2007.

CLARK, I. E. et al. "Deconstructing” scientific research: A practical and scalable pedagogical tool to provide evidence-based science instruction. PLOS Biology, San Francisco, v. 7, n. 12, dez. 2009.

CONSTANTIN, A. Ciência e rebeldia. Opinião, 3 set. 2020.Disponível em:

http://pioneiro.clicrbs.com.br/rs/cultura-e-tendencias/noticia/2020/09/andre-costantin-cienciae-rebeldia-13044929.html. Acesso em: 20 set. 2020.

DAVIES, P. The demon in the machine. Penguin, 2019.

DAVIS, J. H. Framing education as art: the octopus has a good day. International Journal of Education \& the Arts, Pennsylvania State University, v. 6, n. 3, p. 1-16, 2005.

DEMO, P. Saber pensar é questionar. LiberLivro, 2010.

DEMO, P. Teologia da prosperidade. 2017. Disponível em:

https://docs.google.com/document/d/1aRWvy4PSBUQDeKg2iKLoug56Zye0tI1AsVjEVXw3 16o/pub. Acesso em: 20 set. 2020.

DEMO, P. BNCC: ranços e avanços. 2019. Disponível em:

https://drive.google.com/file/d/1iNN-LQuf-9rJe6wFQoH19kQzUKqjzDBj/view. Acesso em: 20 set. 2020. 
DEMO, P. Escola e cuidado. 2019a. Disponível em: https://drive.google.com/file/d/1XKQDqJHfNMFEnN2gVF1n6yZmEmoYkS34/view. Acesso em: 20 set. 2020.

DEMO, P. Educação à Deriva: à direita e à esquerda: instrucionismo como patrimônio nacional. 2020. Disponível em: https://drive.google.com/file/d/10nMlgL8N9GKFgwtnbLbIn7GQf0HdyA4/view. Acesso em: 20 set. 2020.

DEMO, P. Por que tristeza não tem fim, felicidade sim? 2020a.Disponível em: https://drive.google.com/file/d/1ad-U9Jw8yPf48sQrTU8HHTUm3k2dWAn_/view. Acesso em: 20 set. 2020 .

DYSON, F. The scientist as rebel. New York: New York Review Books, 2006.

GOBER, M. An end to upside down thinking: dispelling the myth that the brain produces consciousness, and the implications for everyday life. New York: Waterside Press: 2018.

GUNVE, F. Doing (art) education as art (education). In: KNIGHT, L; CUTCHER, A. L. (Eds.). Arts-Research-Education. Studies in Arts-based Educational Research. Springer. 2017. v. 1.

HARARI, Y.N. Sapiens: a brief history of humankind. London: Harper, 2015.

HARARI, Y.N. Homo Deus: a brief history of tomorrow. London: Harper, 2017.

HARRIS, S. Waking up: a guide to spirituality without religion. New York: Amazon, 2014.

HUME, D. An Enquiry concerning human Understanding: and other writings. Cambridge University Press, 2007.

HUXLEY, A. On science and art in relation to education. Collected Essays. 1882.

Disponível em: https://mathcs.clarku.edu/huxley/CE3/ScRe.html. Acesso em: 20 set. 2020.

KAU, A. Deconstruction and science: how post-secondary literary theory applies to scientific understanding. 2001. Disponível em:

http://sites.science.oregonstate.edu/ stetza/ph407H/Deconstruction.pdf. Acesso em 20 set. 2020.

KAUFFMAN. S. A. A world beyond physics: the emergence and evolution of life. Oxford U. Press, 2019.

KIPLING, R. The science of rebellion: a tract for the times (The Imperial South Africa Association). The Kipling Society. 1901. Disponível em:

http://www.kiplingsociety.co.uk/rebellion.htm. Acesso em: 20 set. 2020.

KLEIN, R.G. The Dawn of Human Culture. New York: John Wiley \& Sons, Inc., 2002.

KISIDA, B.; BOWEN, D. H. New evidence of the benefits of arts education. Brooking, 2019. Disponível em: https://www.brookings.edu/blog/brown-center- 
chalkboard/2019/02/12/new-evidence-of-the-benefits-of-arts-education/. Acesso em: 20 set. 2020 .

KRISTIANSEN, C.; LUND, K.; DAMIAN, B. L. Reflections on the project "Art as Education, Education as Art". 2017. Disponível em: https://www.uia.no/studenter-iforskningsprosjekt/reflections-on-the-project-art-as-education-education-as-art. Acesso em: 20 set. 2020.

LASZLO, E. et al. What is reality? The new map of cosmos, consciousness, and existence. New York: SelectBooks, 2016.

LEE, K. F AI Superpowers: China, Silicon Valley, and the new world order. New York: Houghton Mifflin Harcourt, 2018.

MERZ, M.; KNORR CETINA, K. Deconstruction in a "thinking" science: Theoretical physicists at work. Social Studies of Science, v. 27, n. 1, p. 73-111, 1997.

MILANOVIC, B. Capitalism, alone: the future of the system that rules the world. Harvard U. Press, 2019.

MINAYO, M. C. S. Orientação de mestrandos e doutorandos como atividade profissional. Cadernos de Saúde Pública, Rio de Janeiro, v. 35, n. 10, 2019. Disponível em: https://www.scielo.br/scielo.php?script=sci_arttext\&pid=S0102311X2019001200301\&lng=pt\&nrm=iso. Acesso em: 20 set. 2020.

MINAYO, M. C. S.; DEMO, P.; SILVA, R. A. Pessoas com Deficiência (PcD) egressas de uma formação profissional: trabalho e educação. Revista Ibero-Americana de Estudos em Educação, Araraquara, v. 15, n. 4, p. 1703-1729, jun. 2020. ISSN 1982-5587. Disponível em: https://periodicos.fclar.unesp.br/iberoamericana/article/view/13816. Acesso em: 21 set. 2020.

NATALE, C. 2012. Education is an art: not a science. The Wonder of Childhood, 2012. Disponível em: http://thewonderofchildhood.com/2012/03/education-is-an-art-not-a-science/. Acesso em 20 set. 2020.

PARKER, L.; WELCH, C. 3 things you need to know about the science rebellion against Trump. National Geographic, 2017. Disponível em:

https://www.nationalgeographic.com/news/2017/01/scientists-march-on-washington-nationalparks-twitter-war-climate-science-donald-trump/. Acesso em: 20 set. 2020.

PIKETTY, T. Capital and ideology. Harvard U. Press, 2020.

RACHELLE. What does art education mean to you? TinkerLab, 2014. Disponível em: https://tinkerlab.com/art-education-mean/. Acesso em: 20 set. 2020.

RADCLIFFE, J. The science of rebellion (Notes). 2009. Disponível em: http://www.kiplingsociety.co.uk/rg_rebellion1.htm. Acesso em: 20 set. 2020.

RASMUSSEN, D. C. The infidel and the professor: David Hume, Adam Smith, and the friendship that shaped modern thought. Princeton U. Press, 2018. 
RIPLEY, A. The Smartest Kids in the World: And How They Got That Way. New York: Simon \& Schuster, 2013.

ROVELLI, C. Science is rebellion: knowledge relies on throwing out what we think. IAI News - Changing how the world thinks. 2014. Disponível em: https://iai.tv/articles/scienceis-rebellion-auid-455. Acesso em: 20 set. 2020.

SCHUMPETER, J. A. Can capitalism survive? Creative destruction and the future of the global economy. Harper Perennial Modern Classics, 2009.

STEINER, R. The Kingdom of childhood: introductory talks on Waldorf education. Foundations of Waldorf Education, SteinerBooks, 1995.

STEINER, R. The education of the child. Foundations of Waldorf Education, SteinerBooks, 1996.

STEINER, R. et al. Education as an Art. SteinerBooks, 1988.

ZHAO, Y. Who is afraid of the big bad dragon: why China has the best (and the worst) education system in the world. San Francisco: Jossey-Bass, 2014.

ZHAO, Y. What works may hurt: side effects in education. Teachers College Press, 2018.

ZHAO, Y.; EMLER, T. E.; SNETHEN, A.; YIN, D. An education crisis is a terrible thing to waste: how radical changes can spark student excitement and success. Teachers College Press, 2019.

ZIEGFELD, E. Education and art: a symposium. UNESCO, 1954. Disponível em: https://unesdoc.unesco.org/ark:/48223/pf0000000457. Acesso em 20 set. 2020.

ZIMMERMANN, H. Waldorf-Pädagogik weltweit. Freunde der Erziehungskunst, 2001.

\section{Como referenciar este artigo}

DEMO, P.; MINAYO, M. C. S.; SILVA, R. A. Educação: arte como arte do rompimento ou da desconstrução. Rev. Sem Aspas, Araraquara, v. 9, n. 1, p. 120-139, jan./jun., 2020. e-ISSN: 2358-4238. DOI: https://doi.org/10.29373/sas.v9i1.14213

Submetido em: 10/05/2020

Revisões requeridas: 20/07/2020

Aprovado em: $25 / 08 / 2020$

Publicado em: 30/09/2020 